DIW BERLIN

Discussion

Papers

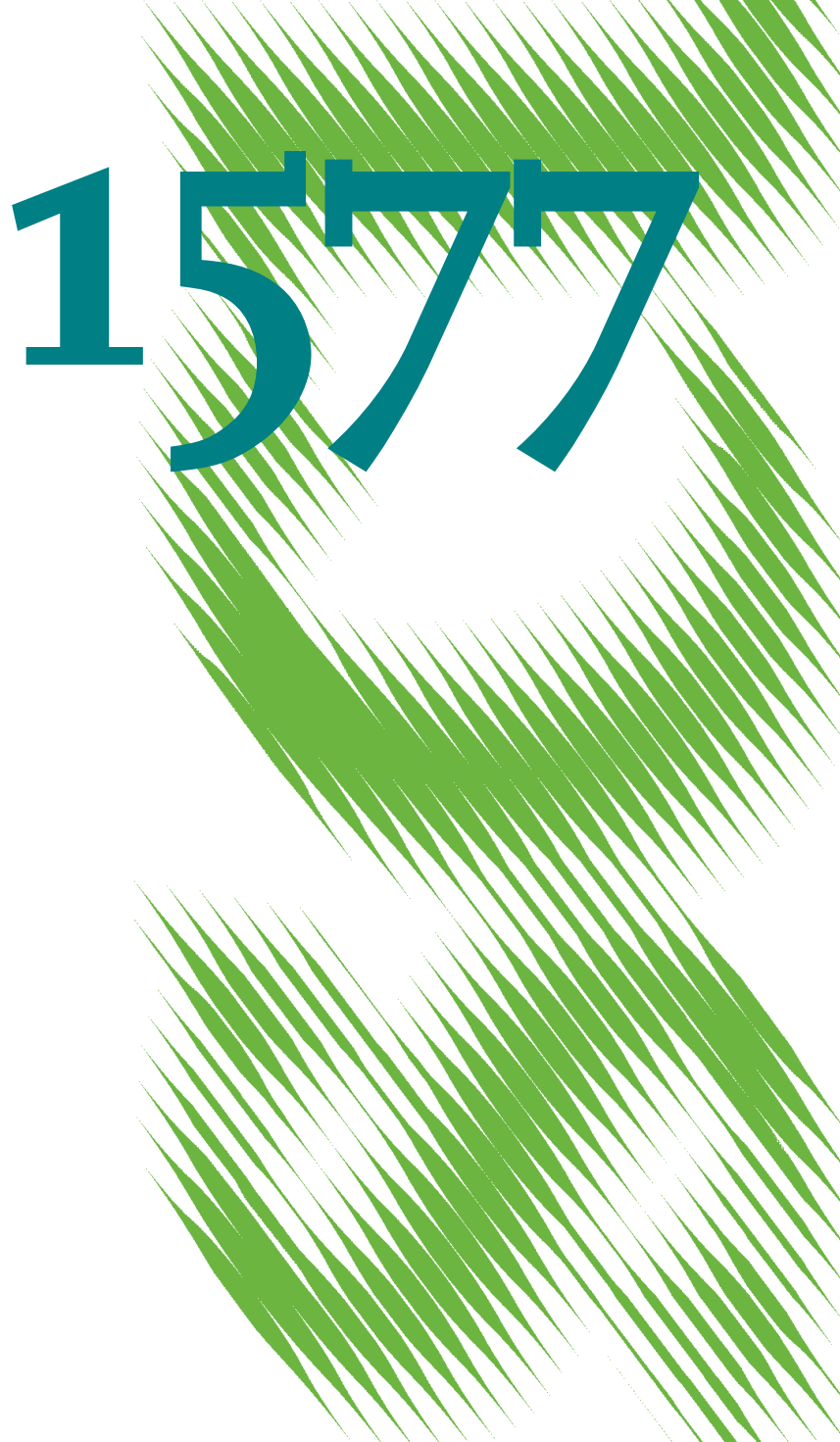

Electrification of a City Bus Network:

An Optimization Model for Cost-Effective

Placing of Charging Infrastructure and Battery

Sizing of Fast Charging Electric Bus Systems 
Opinions expressed in this paper are those of the author(s) and do not necessarily reflect views of the institute.

IMPRESSUM

(C) DIW Berlin, 2016

DIW Berlin

German Institute for Economic Research

Mohrenstr. 58

10117 Berlin

Tel. +49 (30) $89789-0$

Fax +49 (30) $89789-200$

http://www.diw.de

ISSN electronic edition 1619-4535

Papers can be downloaded free of charge from the DIW Berlin website:

http://www.diw.de/discussionpapers

Discussion Papers of DIW Berlin are indexed in RePEc and SSRN:

http://ideas.repec.org/s/diw/diwwpp.html

http://www.ssrn.com/link/DIW-Berlin-German-Inst-Econ-Res.html 


\title{
Electrification of a city bus network - An optimization model for cost-effective placing of charging infrastructure and battery sizing of fast charging electric bus systems
}

\author{
Alexander Kunith $^{1}$, Roman Mendelevitch ${ }^{2}$, Dietmar Goehlich ${ }^{3}$ \\ ${ }^{1,3}$ Department Methods for Product Development and Mechatronics Technische Universität Berlin
}

Strasse des 17. Juni 135, 10623 Berlin, Germany

alexander.kunith@tu-berlin.de

${ }^{2}$ German Institute for Economic Research (DIW Berlin), Mohrenstraße 58, 10117 Berlin, Germany, and Workgroup for Infrastructure Policy (WIP), Technische Universität Berlin, Strasse des 17. Juni 135, 10623 Berlin, Germany

\begin{abstract}
The deployment of battery-powered electric bus systems within the public transportation sector plays an important role to increase energy efficiency and to abate emissions. Rising attention is given to bus systems using fast charging technology. This concept requires a comprehensive infrastructure to equip bus routes with charging stations. The combination of charging infrastructure and bus batteries needs a reliable energy supply to maintain a stable bus operation even under demanding conditions. An efficient layout of the charging infrastructure and an appropriate dimensioning of battery capacity are crucial to minimize the total cost of ownership and to enable an energetically feasible bus operation. In this work, the central issue of jointly optimizing the charging infrastructure and battery capacity is described by a capacitated set covering problem. A mixed-integer linear optimization model is developed to determine the minimum number and location of required charging stations for a bus network as well as the adequate battery capacity for each bus line of the network. The bus energy consumption for each route segments is determined based on individual route, bus type, traffic and other information. Different scenarios are examined in order to assess the influence of charging power, climate and changing operating conditions. The findings reveal significant differences in terms of needed infrastructure depending on the scenarios considered. Moreover, the results highlight a trade-off between battery size and charging infrastructure under different operational and infrastructure conditions. The paper addresses upcoming challenges for transport authorities during the electrification process of the bus fleets and sharpens the focus on infrastructural issues related to the fast charging concept.
\end{abstract}

JEL codes: C61; L92; R42

Keywords: electric bus, charging infrastructure, fast charging, cost optimization, capacitated set-covering problem

\section{Introduction}

The implementation of alternative drive technologies such as battery-powered electric bus systems is of major importance to decrease the exhaust gas emissions of public transportation. In order to evaluate the possible substitution of currently deployed conventional diesel buses, transport companies around the globe are intensifying electric bus trials [1-3]. Rising attention has been recently received by bus systems comprising fast charging technology. This application follows the opportunity charging concept which assumes a comprehensive infrastructure of charging points to recharge the buses in operation by using high charging power [4-6]. Importantly, compared to electric trolley bus systems, the fast charging concept does not require continuous connection to overhead wires along the entire bus line. Potential charging spots are the bus stops of the served bus line. Through fast charging en route, operational deployment similar to conventional diesel buses is feasible in terms of range and operating time. Opportunity charging bus systems are characterized by smaller dimensioned batteries compared to overnight slow-charging buses. The smaller dimensioned batteries results in lower vehicle weight, higher passenger capacity and lower 
investment costs for batteries [7]. Hence, these bus systems feature relatively low bus investment cost compared to overnight charging or fuel cell buses. From a total cost of ownership perspective this approach has a clear advantage under current conditions [8-10].

However, the system imposes high infrastructure planning requirements since bus routes have to be equipped with sufficient charging points. The number of charging points in turn has significant influence on the initial cost [11]. Furthermore, considering the vehicle cost of an electric bus, the batteries amounts up to one third of the total vehicle cost including battery replacement. Therefore, battery capacity needs to be optimized in accordance to the operational requirements to minimize required investments. Due to the interdependence of the energy supply through fast charging and the battery capacity, to comply with operational requirements a joint examination is necessary.

The remainder of this paper is organized as follows. The next section details relevant aspects for charging infrastructure planning and outlines pertinent literature. Section 2 explains the methodology used by introducing the optimization model. In Section 3 the underlying energy consumption simulation is presented. Section 4 describes the case study and the respective assumptions and operational conditions on the bus network, the battery and charging technology as well as input cost parameters. Next, simulation results on required charging infrastructure and batteries are analyzed under different technology, operational and planning scenarios and are discussed in Section 5. Finally, the paper concludes with a summary and outlook in Section 6.

\subsection{Key constraints influencing fast charging infrastructure planning}

Integrated planning of charging infrastructure for electric fast charging bus systems, has to take into account various information, restrictions and constraints that can be structured in two different categories:

i) Bus Operation and Infrastructure: Information on the topology of bus network, including shared stops needs to be captured, to account for cost synergies when installing fast charging stations. Moreover, data on daily operation hours and dwell times are required. Dwell times are determined by the bus route schedule and might vary according to the type of the bus stops. Additionally, data on the bus fleet configuration needs to be added to account for different specific electricity consumption and resulting infrastructure requirements. Furthermore, information on availability of infrastructure on e.g., landmarked areas and lacking energy grid capability is required. Respective bus stops should be identified and excluded from further investigations.

ii) Technology: Data on charging power and battery specifications is needed. The energy which can be recharged at charging stations depends on the dwelling time (which is determined by operational planning), the available charging infrastructure (i.e. grid power and charging power), and on the battery type and the battery's state of charge (SOC) which is of particular significance for actual bus operation. The battery's charging behaviour in terms of the charging power and the SOC can be described by a non-linear function. Long-term charging behaviour also depends on the depth of discharge (DOD) which is intended to be kept relatively small to improve the longevity of a battery [12-13].

\subsection{Literature review}

The emerging infrastructural challenges related to the deployment of alternative-powered vehicles such as electric vehicles (EV) are attracting widespread interest and have been recently addressed in the pertinent literature. Most of the research studies have been motivated by increasing market penetration of private electric vehicles. Thus, research has been conducted in the field of distributing charging point locations for passenger electric vehicles. Frade [14] developed a maximum coverage location problem (MCLP) model to determine the optimal locations for a fixed number of public charging stations for an urban area to maximize the demand covered. Wei [15] introduced a demand coverage location model for electric taxi charging location considering the spatial dimension of demand as well as the temporal dimension such as time of demand and service duration in order to maximize the electric taxi and charging service. The approach uses taxi GPS data for an optimized placement of charging station. Sadeghi-Barzani [16] established a model for the optimal placing and sizing of fast charging stations for electric vehicles. The approach comprises a mixed-integer non-linear (MINLP) optimization in order to minimize the total cost associated with supplying the energy demand of $\mathrm{EV}$ based on the number of charging stations. By comparing two different approaches to identify the optimal location of fast charging stations, Cruz- 
Zambrano [17] highlight the importance of considering installation cost. The two methodologies are based on Flow-Capturing Location-Allocation Model (FCLM) and differ in their objective function. While the first is to maximize the amount of flows captured by a fixed number of charging facilities, the second aims at minimizing the cost of installing a variable number of fast charging stations capturing a given minimum amount of flow. In their study, He [18], compared three different facility location models to identify the optimal location of public electric vehicle charging stations. In addition to the determination of ideal charging locations, the work examines the cost-effectiveness of the infrastructure layout by assessing the impact of an increasing number of charging stations on the demand to be covered. Furthermore, planning aspects are taken into account by evaluating the stability of solutions regarding a progressive infrastructure expansion.

Liu [19] introduced a two-step screening method to identify the optimal sites of EV charging stations taking into account environmental factors and service radius, followed by the application of a mathematical algorithm to solve charging stations' optimal capacities. By employing an integer programming optimization model adapted from a Vehicle Routing Problem (VRP), Worley [20] presented an approach to perform the routing of commercial EV and distribution of charging stations simultaneously. Also based on VRP, Kameda [21] set up a model using the Node Insertion Algorithms for solving the location problem in the context of an on-demand electrical minibus system in Japan. The placement of charging stations is finally determined by means of taxi probe data. Furthermore, Barco [22] defined a VRP aiming to find a set of minimum consumption routes, so that the transport demand and predefined operational constraints are fulfilled. In addition to classical VRP, the objective function takes into account the recharging cost including varying daily energy tariffs and battery degradation cost. An alternative technique is proposed by Boostani [23] for an analogous location problem of a compressed natural gas refuelling station. The method applies a heuristic algorithm to solve the arc demand coverage problem of determining the optimal location of refuelling station such that the flow demands are met and capital expenditure is minimized.

However, public transport buses within a transport networks in general differ from the behaviour of passenger electric vehicles. Bus network operations feature predetermined and fixed scheduled routes. Hence, optimization models allocating a given number of charging points or analysing traffic flows of individual cars purposing to maximize the covered demand are not an appropriate approach to solve the infrastructural issue for fast charging bus systems.

Substantial research has been done on the bus Vehicle Scheduling Problem (VSP) for conventional diesel buses optimizing the number of vehicles, the operational time and the total cost [24-25]. Only few studies are tailored to the different technical features and operating characteristics of electric buses [26]. Zhu [27] dedicated his investigation to establish a single depot vehicle scheduling model for a battery-switching station. The multi-objective model minimizes the number of vehicles to serve all trips and the number of standby batteries reserved for the continuous operation as well as determines the energy supply to meet daily demand. Concerning the charging schedule of fast charging electric buses, De Filippo [28] developed a simulation model to examine how electric bus charging patterns and queuing times are affected by the number of chargers deployed in the system and the charging policy employed. Thus, the study determines the fleet and infrastructure requirements for the investigated bus lines to substitute diesel buses. Paul [29] and Rogge [30] analyse the possible implementation of electric bus systems for a bus network based on the vehicle scheduling and infrastructure planning. Assuming that all charging stations are located at terminal bus stops, both studies present an approach to determine the electrification potential of bus networks. However, the studies mentioned either address the topic of adapting existing vehicle scheduling and accordingly creating electric bus customized service schedules, or modelling the bus network with predetermined charging locations based on solely energetic values.

The efficient application of the opportunity charging concept requires a cost-optimized distribution of charging stations. Thereby, a trade-off between the battery capacity (battery cost and weight) and the number of installed charging points has to be made while ensuring that sufficient energy is replenished to comply with the operation schedule. Based on existing work and the approach introduced in [31-32], this paper presents an advanced mixed-integer linear optimization model. The model solves a capacitated set covering problem to determine the minimum required number and the respective location of charging stations and required battery sizes for each bus line in the network complying with the original operational schedule of the diesel bus. The network perspective allows identifying cost synergies when planning the charging infrastructure for several bus lines at once. Hence, the simulation model considerably supports the optimal infrastructure layout of fast charging bus systems. 


\section{Methodology - optimization model to jointly determine the number and location of fast charging spots and required battery size}

In the following section, a general mixed-integer optimization model is described that is able to capture the main features of an electric bus system as described in the section above. While reflecting network, operational and technical constraints, it determines the cost-minimal trade-off between charging stations and battery size for each line and respective charging profiles for each bus in the system.

This modelling approach builds on and further develops a model first presented in [32]. A full list of sets, parameters and variables can be found in the Appendix (Table A.1). In the following all sets are giving with single letters, all parameters are denoted in capital letter and all variables are denoted in small letters. The objective function (1) in the original version of the model minimizes the number of charging stations, the resulting construction cost for the charging station $\left(C^{\text {STATION }}\right)$ and the transformer stations $\left(C^{\text {TRANSF }}\right)$ which can be shared with several charging points at one station, while serving the required daily demand. The binary variable $z_{i}$ indicates whether a charging station is built at stop $i$, while $z_{i d}^{\text {ident }}$ identifies whether a transformer station is built at station $i d$. In the new version of the model, a third term which represents the battery costs is added. It is the sum of buses required to perform the service $\left(N U M_{b}\right)$ multiplied with the binary variable $b a t_{b, v}$ which indicates the battery capacity chosen for a particular line $b$ and again multiplied with the respective individual battery costs $C_{v}^{B A T E R Y}$.

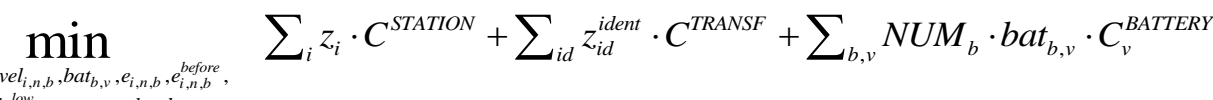

$$
\begin{aligned}
& \begin{array}{l}
z_{i}, z_{i d e}^{\text {ident }}, \text { level }_{i, n, b}, \text {,at }_{b, v}, e_{i, n, b}, e_{i, n, b}^{\text {before }} \\
\text { idleigh }_{i, n, b}, \text { idle }_{i, n, b}, \text { soc }_{i, n, b, v}, \operatorname{load}_{i, n, b}
\end{array}
\end{aligned}
$$

Numerous constraints are necessary to represent the network layout and the technical parameters of the charging process. A nodal energy balance constraint (2) ensures that the current energy level $e_{j, n, b}^{\text {befre }}$ at each stop $j$, for each trip $n$ and for each line $b$, is equal to the energy level at the previous station $\left(e_{i, n, b}\right)$ minus consumption for traveling from the previous stop $\operatorname{CONSUME}_{i, j, b, n}{ }^{1}$ plus energy recharged at the current station (loading power in the high power segment $L P_{b}^{\text {high }}$ times a variable loading time in the high power loading $\left.i d l e_{j, n, b}^{h i g h}\right)$. A distinction between $e_{i, n, b}^{\text {befre }}$ and $e_{i, n, b}$ which generally capture the same value, becomes necessary due to the complex charging process and is described further later in this section. This energy balance applies to all stops that are adjacent on a line $\left(s_{j, n, b}\right)$ except for the first stop of each tour FIRSTSTOP $_{n, b}$. For these stops the alternative energy balance (3) applies, where $\operatorname{LASTSTOP}_{n, b}$ is the bus stop just before the first stop.

$$
\begin{aligned}
& e_{j, n, b}^{\text {before }}=e_{i, n, b}-\text { CONSUME }_{i, j, b, n}+\text { LP }_{b}^{\text {high }} \cdot \text { idle }_{j, n, b}^{\text {high }} \quad \forall j \neq \text { FIRSTSTOP }_{n, b}, n, b \mid s_{i, j, b}>0 \\
& e_{j, n, b}^{\text {befree }}=e_{i, n-1, b}+\text { LP }_{b}^{\text {high }} \cdot \text { idle }_{j, n, b}^{h i g h} \quad \forall j=\text { FIRSTSTOP }_{n, b}, i=\text { LASTSTOP }_{n, b}, n, b
\end{aligned}
$$

Additional constraints specify the initial charging level of the battery as well as the boundary constraints for specific cases as "depot to first stop" and "return from final stop". The absolute lower bound $\left(\operatorname{LBOUND}_{b}\right)$ and upper bound are specified in (4) and (5), where in both cases the chosen battery size is identified by summing over all possible battery sizes $C A P_{v}^{B A T T E R Y}$ multiplied with the binary decision bat $_{b, v}$ variable that flags the chosen option.

$$
\begin{array}{ll}
e_{i, n, b}-\operatorname{CONSUME}_{i, j, b, n} \geq \mathrm{LBOUND}_{b} \cdot \sum_{v} \text { CAP }_{v}^{B A T T E R Y} \cdot \text { bat }_{b, v} & \forall j, n, b \mid s_{i, j, b}>0 \\
e_{i, n, b}-\mathrm{CONSUME}_{i, j, b, n} \leq \sum_{v} \operatorname{CAP}_{v}^{B A T T E R Y} \cdot \mathrm{bat}_{b, v} & \forall j, n, b \mid s_{i, j, b}>0
\end{array}
$$

To approximate the non-linear form of the charging power function of a battery, the function is split into two different segments divided by a threshold $\left(\right.$ THRESHOLD $_{b}$ ). The high charging power $\boldsymbol{L} \boldsymbol{P}_{b}^{\text {high }}$ applies for charging below the threshold and reduced charging power $L P_{b}^{\text {low }}$ applies above. Charging time can be split

\footnotetext{
${ }^{1}$ The parameter consume $_{i, j, b, n}$ also captures the routes of the lines by only allowing to travel between adjacent $i$ and $j$ for a given line $b$.
} 
between the two segments with $i d l e_{j, n, b}^{\text {high }}$ for high power charging and $i d l e_{j, n, b}^{\text {low }}$ for the duration of reduced charging power. The sum of both charging times cannot exceed the idle time at a stop, reduced by pre-and post-processing time before and after charging (6). Maximum charging power can only be performed if the binary variable level $_{i, n, b}$ is flagged to one (7). The SOC of the battery is monitored using the auxiliary variable $s_{s} c_{\mathrm{i}, n, b, v}$ and is used to determine the current charging efficiency. $S_{0} c_{\mathrm{i}, n, b, v}$ is only non-zero for the chosen battery option bat $_{b, v}$ (8) and only one of the options can be chosen (9). Moreover, if a battery option is chosen, $s O c_{\mathrm{i}, n, b, v}$ is set to current SOC using (10), where $O V E R_{v}^{\text {BATTERY }}$ is an auxiliary parameter (the quotient of maximum battery size and the battery size of option $v$ ).

Equation (11) guarantees that the SOC after maximum charging power is applied cannot exceed the threshold, otherwise level $_{i, n, b}$ would flag to zero and maximum charging power would not have been possible in the first place. Equation (12) calculates the final battery level by adding charging with limited power.

$$
\begin{aligned}
& \text { idle }_{i, n, b}^{\text {high }}+\text { idle }_{i, n, b}^{\text {low }} \leq \text { IDLETIME }_{i, n, b}-\text { PREPROCESSING }_{b}-\text { POSTPROCESSING }_{b} \\
& 1 / \text { IDLETIME }_{i, n, b} \cdot \text { idle }_{i, n, b}^{\text {high }} \leq \text { level }_{i, n, b} \\
& \operatorname{sOc}_{i, n, b, v} \leq \text { bat }_{b, \mathrm{v}} \\
& \sum_{v} \text { bat }_{b, v}=1 \\
& \text { OVER }_{v}^{\text {BATTERY }} \cdot\left(1-\text { bat }_{v, b}\right)+\operatorname{soc}_{i, n, b, v} \geq e_{i, n, b}^{\text {before }} / \text { CAP }_{v}^{\text {BATTERY }} \\
& \sum_{v} \operatorname{soc}_{i, n, b, v} \leq \text { THRESHOLD }_{b}+\left(1-\text { level }_{i, n, b}\right) \cdot\left(1-\text { THRESHOLD }_{b}\right) \\
& e_{p, n, b}=e_{p, n, b}^{\text {before }}+\operatorname{LP}_{b}^{\text {low }} \cdot \text { idle }_{p, n, b}^{l o w}
\end{aligned}
$$

However, charging with any power can only be performed if a charging station is built (13). Moreover, the required number of transformer stations is determined using (14). MAXSTOPS id is the maximum number of stops at one station, and the right-hand side of the inequality gives the number of installed charging stations at one stop that is not already equipped with a transformer station due to grid access of the metro network.

$$
\begin{aligned}
& 1 / \text { IDLETIME }_{i, n, b} \cdot\left(\text { idle }_{i, n, b}^{\text {high }}+\text { idle }_{i, n, b}^{\text {low }}\right) \leq z_{i} \\
& z_{\text {idd }}^{\text {ident }} \cdot \text { MAXSTOPS }_{i d} \geq \sum_{i \in\left\{\text { ident }_{i}=\text { ident_id }_{\text {idd }} \cap n o_{-} \text {train }_{i}\right\}} z_{i}
\end{aligned}
$$

\section{Energy consumption simulation}

The optimal distribution of charging points fundamentally results from the efficient replenishment of the bus energy consumption. Therefore, it is essential that the route specific energy consumption is represented adequately. Similar to internal-combustion vehicles, several factors such as vehicle weight, topography of operation area and energy efficiencies influence the total energy consumption. In contrast, full-electric buses feature specific consumptions characteristics, in particular in relation to climate conditions with respect to air-conditioning and heating due to low engine waste heat. Thus, significantly higher energy consumption for extreme weather conditions has to be taken into account [33].

However, the energy consumption cannot be assumed constant over the entire route service. The consumption rather varies with the current circumstances the bus is exposed to. The simulation of the energy consumption can be conducted based on recorded driving profiles for each bus line covering the daily driving characteristics [34]. Such driving profiles are rarely available for an entire bus network. The presented approach can be applied using different raw data formats depending on the availability of highresolution driving profiles. The data collection for simulation is straightforward and uses only existing data and parameters known to the bus operator.

The energy consumption is determined for each route section and time interval, individually. The sectioning of the route is conducted in accordance with the bus stops (distance between bus stops) and the section's characteristics such as vehicle velocity are captured. Since bus routes feature different operating conditions, 
it is required to collect the relevant route section data for all bus lines considered in order to manually generate driving profiles. Since some bus route parameters like velocity are usually given as an average speed over the entire bus line, an additional correction parameter is introduced to indicate route segments with significant deviation from the average value.

Apart from the geographical segmentation, a time-dependent examination has to be introduced due to varying service conditions. During daily operation schedule, parameters such as dwell times, frequencies and travelling times vary in order to cope with changing traffic and passenger volumes in peak hours. In the presented approach, daily operation is segmented reflecting the time-dependent influence of the operational environment. For each time interval, the average passenger occupancy is assigned and schedule parameters can be adjusted specifically.

The influence of traffic volume is set as a function of both time and location and is merged in the above mentioned correction parameter named Volume of Traffic (VoT). Based on the geographical and timedependent segmentation, the energy consumption is simulated and values are finally assigned to every defined bus route section. However, the ambient temperature also varies during the daily operation and the effect on the energy consumption caused by the temperature is captured separately in the model as explained below.

Overall, through route sectioning and the application of time intervals, the different stress situations caused by exogenous factors during the daily operation can be reproduced. This approach is favoured over applying a worst-case scenario assuming constant extreme conditions over the entire day of operation. For instance, the maximum passenger occupancy is only reached for a very small numbers of service trips while the average occupancy rate is around 20 percent for public bus transport in Germany [35].

The energy consumption is calculated according to DIN 70030 [36]. The simulation model encompasses the total tractive force $F_{\text {Total }}$ consisting of air resistance, rolling resistance, climbing resistance and acceleration resistance. Complementary, the consumption of auxiliaries such as air-conditioning and heating is added, modelled by the electrical power over the usage duration as a function of the ambient temperature. Table 1 and Table 2 shows the simulation parameters applied for calculating the energy consumption. Since the deployed vehicle type usually varies with the bus route, three vehicle types are considered in the presented study and assigned to each bus line. The model distinguishes between a standard $12 \mathrm{~m}$ bus (SB), $18 \mathrm{~m}$ articulated bus (AB) and double decker bus (DD).

Table 1: Vehicle parameters

\begin{tabular}{lclccc}
\hline Parameter & Value & Parameter & \multicolumn{3}{c}{ Value } \\
\hline Air drag coeff. & 0.66 & Vehicle speed $\left[\frac{\mathrm{m}}{\mathrm{s}}\right]$ & \multicolumn{2}{c}{ varies } & \\
Air density $\left[\frac{\mathrm{kg}}{\mathbf{m}^{2}}\right]$ & 1.29 & Total vehicle efficiency $\left(\eta_{\mathrm{t}}\right)$ & & 0.733 & \\
Gravitational force $\left[\frac{\mathrm{m}}{\boldsymbol{s}^{2}}\right]$ & 9.81 & & SB & AB & DD \\
Gradient angle $(\alpha)$ & varies & Cross-sectional area $\left[\mathrm{m}^{2}\right]$ & 8.28 & 8.28 & 10.35 \\
Rolling resistance coeff. & 0.008 & Vehicle curb weight $[, 000 \mathrm{~kg}]$ & 12.5 & 17.5 & 18.5 \\
\hline
\end{tabular}

The total energy consumption for a route segment as the distance between bus stop $i$, and $j$ on bus line $b$ at trip $n$ is finally determined by

$\operatorname{CONSUME}_{i, j, b, n}=\left(\frac{\left(F_{\text {Totali } i, b, n} \cdot S_{i, j, b}\right)}{\eta_{t}}+E_{a u x i, j, b, n}\right) \cdot V o T_{i, j, b, n}$

where for each route segment $i, j$ on bus line $b$ at trip $n F_{\text {Total } i, j, b, n}$ is the total tractive force, $\boldsymbol{s}_{\boldsymbol{i}, \boldsymbol{j}, \boldsymbol{b}}$ is the length of the route segment, $E_{a u x} x_{i, j, b, n}$ is the energy consumption of the auxiliary devices for route segment and $V o T_{i, j, b, n}$ is the correction parameter for segment. The time interval is derived from the number of trips.

The total vehicle efficiency is composed of the efficiency of the electric machine, traction converter, battery converter and further electronics. The efficiency values refer to [37] and [38]. The total vehicle mass is the sum of the curb weight including battery (given in Table $1 \mathrm{for}$ SB with $60 \mathrm{kWh}$ and AB as well as DD with $90 \mathrm{kWh}$ battery size) and the passenger load for a specific bus line and time interval. The daily average electrical power for the auxiliary devices of each bus type is shown in Table 2. It is assumed that the 
required energy of heating, ventilation and air-conditioning (HVAC) and other devices is provided by the battery. The values presented in Table 2 are simulated for different ambient temperatures scenarios using an electric positive temperature coefficient (PTC) heating and a roof top air-conditioner with electric compressor according to methodology of [39-40]. Referring to these studies, the set temperature for the passenger cabin is $20^{\circ} \mathrm{C}$ for heating mode and $25^{\circ} \mathrm{C}$ for cooling mode. The values for the $\mathrm{AB}$ is estimated based on vehicle dimension and passenger capacity compared to a SB. The energy consumption for auxiliaries of a $\mathrm{DD}$ is assumed equal to the consumption of an $\mathrm{AB}$.

Table 2: Daily average auxiliary power of an HVAC system using a PTC heating considering different ambient temperatures

\begin{tabular}{lcccccc}
\hline Ambient Tem. & $\mathbf{- 1 5}^{\circ} \mathbf{C}$ & $\mathbf{- 1 0}^{\circ} \mathbf{C}$ & $\mathbf{- 5}^{\circ}$ & $\mathbf{0}^{\circ} \mathbf{C}$ & $\mathbf{1 5}^{\circ} \mathbf{C}$ & $\mathbf{3 0}^{\circ} \mathbf{C}$ \\
\hline Aux. Power SB [kW] & 12.23 & 10.34 & 8.47 & 6.61 & 2.57 & 5.03 \\
Aux. Power AB \& DD [kW] & 17.06 & 14.42 & 11.81 & 9.21 & 3.58 & 7.01 \\
\hline
\end{tabular}

For further investigations it is stated that the required average power of a PTC heater by an ambient temperature of $0^{\circ} \mathrm{C}$ is equal to the power required by a heat pump exposed to a temperature of $-15^{\circ} \mathrm{C}$. Furthermore, for an ambient temperature of $15^{\circ} \mathrm{C}$, the auxiliary power for the HVAC is negligible and thus additionally represents a possible scenario in which the energy for heating is provided by a fossil fuel heater.

\section{Application case - assumptions and operation conditions}

\subsection{Bus network}

For the application case a representative sub-network of the Berlin BVG bus system was chosen as shown in Figure 2. The sub-network includes 17 lines that all operate from the same bus depot with a total network of $350 \mathrm{~km}$ and 134 buses. Moreover, the sub-network features two transport nodes where several lines converge and share the same terminal station. Additionally, the different bus lines have various intersections among each other. For each bus line, two service trips are simulated corresponding to the outward and return trip between different terminal stations. Since the service trips of one bus line can differ in length, for each bus line the route with the maximum length is selected. The dataset is exclusively based on real bus schedules on workday operation in order to cope with the peak demand requirements.

The network holds a high degree of heterogeneity in terms of the bus line profiles. Thus, the route length of the lines as well as the number of bus stops vary significantly between 12-36 km and 14-86 stops, respectively. The selection includes typical bus routes connecting the city centre to the suburbs (e.g. 110), central interconnectors (e.g. 100, M85), hybrid lines (e.g. M48) and rapid bus routes (e.g. X9 airport express). As described in the previous section for each bus route, the segment specific energy consumption is calculated based on the average velocity observed on the line varying from $13-29 \mathrm{~km} / \mathrm{h}$, the time of day (i.e. occupancy rate and expected congestion), relative congestion with respect to centrality of the line segment, and bus type (SB, AB, or DD). Dwelling time at a bus stop depends on the type of stop: For terminal stops, the observed average dwelling times (between 3-21min) are considered. For bus stops with a known high transfer of passengers such as intersections with metro or suburban trains, the dwelling time of 40 seconds is assumed. For all other stops the dwelling time of 20 seconds is predefined. Individual bus stops en route are assigned to exact geographical position in terms of line direction and bus stop locations at crossroads so that the potential for shared charging stations can be realistically assessed. Daily operating hours are up to 21 hours (1am-4am). Finally, the required number of buses for a line is calculated by means of the average turnaround times and average service frequency. However, it is assumed that each vehicle only operate on one fixed route. Despite this, the model would be capable to include vehicle rotation when operating on different bus lines during daily operation by defining artificial bus routes.

\subsection{Battery and fast charging system}

Referring to the earlier section, the battery storage system and the fast charging technology are crucial elements when planning the charging infrastructure. In this study, a lithium-ion based battery is applied. Since very high charging power is applied, certain battery types such as lithium-titanate (LTO) or lithium iron phosphate (LFP) are used preferably in current electric bus projects. The longevity of the battery depends on time and usage. Thus, the battery degradation in terms of capacity fading is divided into cycling and calendar losses. Several studies attribute the capacity fading to the applied charging power, the DOD 
and the initial SOC when the charging process is started [41-42]. In order to limit and decelerate the capacity fading process, the battery is deployed under several constraints. In this case study, it is assumed that in operation the SOC stays within a predefined range. The lower boundary is also defined as the security margin under which the battery level does not drop in operation. The upper level marks the SOC until the maximum charging power can be applied. On exceeding this threshold, the charging power is reduced. In simulation the definition of lower boundary and charging power restriction for high SOC values leads to the effect that charging events are placed within the beneficial SOC range whenever possible. The constraints described are applied equally for all simulated buses and are given as percentages of the battery capacity.

The operational requirements of the bus line within a network can differ significantly depending on the schedule and the route characteristics. Assuming an equal battery capacity for each bus line would inevitably lead to an oversizing and avoidable cost. Thus, the battery capacity of the bus is determined individually for each bus line based on the energy consumption simulation. However, an individual capacity of each bus line would limit the flexibility of bus deployment since the vehicles are predestined to the bus lines they are originally assigned to. In this investigation, it is assumed that capacity variations are limited to three different battery sizes for each bus type in order to ensure operational flexibility and to confine technical complexity. The optimization model determines the optimal battery capacity. The battery capacity in turn varies according to the three different bus types and bus lines between $60 \mathrm{kWh}, 90 \mathrm{kWh}$ or $120 \mathrm{kWh}$ for $\mathrm{SB}$ and $90 \mathrm{kWh}, 120 \mathrm{kWh}$ or $150 \mathrm{kWh}$ for $\mathrm{AB}$ and DD.

Fast charging can be realized through conductive and inductive energy transfer. Currently available and tested charging technologies enable conductive fast charging of up to $500 \mathrm{~kW}$ and inductive charging of up to $200 \mathrm{~kW}$ using a battery as internal storages [43-44]. The examined variations of all parameters are listed in detail in the scenario description section.

\subsection{Cost calculation parameters}

Table 3 presents the parameters for the bus procurement for each bus type as well as the respective battery capacity and the cost of the fast charging station, including the grid connection and construction expenses as well as additional cost for a power transformer. The cost data for SB and AB are available from several sources [45-46]. The cost parameters shown are derived for electric bus systems recently available on the German market [9] [47-50]. The low market penetration of electric bus systems still leads to relatively high procurement cost compared to diesel buses. In particular, electrified double deckers are rarely deployed in current demonstration projects and only one bus manufacturer has electric double deckers in its portfolio for the European market [51]. Thus, the costs for a double decker are estimated as stated in Table 3. It can be expected, that with increasing demand and higher production output numbers, the acquisition costs of electric bus systems will further decrease. The cost for the fast charging station corresponds to a conductive charging system with a charging power of $300 \mathrm{~kW}$ including civil works. In practice, the cost might vary due to different construction complexity at the bus stop locations.

Table 3: Cost data of electric bus and fast charging infrastructure

\begin{tabular}{lccc}
\hline Bus type & SB & AB & DD \\
\hline Electric bus w/o battery $[€]$ & 420,000 & 500,000 & 550,000 \\
LTO-battery incl. replacement $[€ / \mathrm{kWh}]$ & & 2,000 & \\
Fast-charging components and civil works $[€]$ & & 320,000 & \\
Power transformer $[€]$ & & 40,000 & \\
\hline
\end{tabular}

The charging infrastructure planning is ideally conducted from the network perspective in order to leverage synergies. This implies that the simulation model incorporates network specific information such as bus line intersections and grid accessibility, assuming that the potential multiple use of the charging infrastructure leads to cost savings. Cost savings are realised if existing infrastructure such as power transformers for the metro network can be used or several charging stations can be placed at the same bus stop. In order to determine the potential of using existing grid infrastructure, the location of existing power transformers within the bus network is analysed and where available assigned to a bus stop. In such a case the cost for a power transformer is omitted and only the cost for the charging station equipment and construction cost are applied. Multiple installation of charging points at the same bus station also leads to cost savings accounting only for one power transformer instead of several. If bus stops en route are 
geographically identical, it is assumed that the charging station can service several bus lines [28] [52]. Thus, only the cost for one charging station including power transformer is considered.

\subsection{Scenario description}

The following section provides an overview of investigated parameter variations compared to the baseline scenario. For the base scenario, technical and operational assumptions are presented in Table 4. All assumptions are applied to the entire bus network.

Table 4: Baseline scenario

\begin{tabular}{ll}
\hline Baseline scenario & \\
\hline Maximum charging power & $300 \mathrm{~kW}$ \\
Battery usage & Security margin set to $30 \%$, max. charging power until $80 \%$ SOC \\
Battery capacity & 60,90 or $120 \mathrm{kWh}$ for SB and 90,120 or $150 \mathrm{kWh}$ for AB and DD \\
Daily operating time & 21 hours \\
Auxiliary power & $6.61 \mathrm{~kW}$ for SB, $9.21 \mathrm{~kW}$ for AB and DD \\
Roll-out strategy & Network based \\
\hline
\end{tabular}

The parameters charging power and battery capacity are derived from current demonstration projects. The daily operating time reflects a bus operation in a metropolitan area. The baseline scenario as shown in Table 4 is conducted with a maximum charging power of $300 \mathrm{~kW}$, a security level of $30 \%$ battery capacity as well as charging with maximum power until $80 \%$ SOC is reached. The daily operating duration is given with 21 hours and the average auxiliary power is set to $6.61 \mathrm{~kW}$ for the SB and $9.21 \mathrm{~kW}$ for $\mathrm{AB}$ and DD which represents $0^{\circ} \mathrm{C}$ ambient temperature scenario using a PTC heating or equivalent a $-15^{\circ} \mathrm{C}$ temperature scenario deploying a heat pump. The roll-out strategy is stated as network based assuming that the bus lines are electrified from a network perspective taking cost synergies into account. Contrarily, one scenario variation assumes a single line expansion which means that for every bus line the electrification requirements are evaluated independently. In addition, variations in charging power, average auxiliary power, battery usage and dwell times are simulated as listed in Table 5. The scenario dwell times reflects to the fact that the dwell times are usually not constant over the daily operation (e.g. changed frequencies, delays). Thus, simulations are conducted assuming that for peak hours the dwell times are reduced to $80 \%$ and extended to $200 \%$ (doubled) compared to the baseline scenario.

Table 5: Scenario overview and parameter variations

\begin{tabular}{|c|c|}
\hline Scenario variation & \\
\hline Scenario Charging & $200 \mathrm{~kW} / 500 \mathrm{~kW}$ \\
\hline Scenario Battery usage & $\begin{array}{l}\text { Security margin of } 15 \% \text { and max. charging to } 90 \% \text { of } \\
\text { SOC }\end{array}$ \\
\hline Scenario Temperature & $-15^{\circ} \mathrm{C} /-10^{\circ} \mathrm{C} /-5^{\circ} \mathrm{C} / 15^{\circ} \mathrm{C} / 30^{\circ} \mathrm{C}$ \\
\hline $\begin{array}{l}\text { Scenario Dwell times } \\
\text { Scenario Roll-out strategy }\end{array}$ & $\begin{array}{l}\text { Extended to } 200 \% \text { / reduced to } 80 \% \\
\text { Single line expansion }\end{array}$ \\
\hline
\end{tabular}

For the sensitivity analysis only one parameter is varied for each simulation. In total 12 simulations are performed.

\section{Results and discussion}

In this study, an optimization model for the electrification of a bus network with fast charging buses was developed and applied to determine the required charging infrastructure and battery capacities to electrify a diesel bus subnetwork of Berlin. Simulations based on real network data and different scenarios reflecting changing operation conditions were carried out. It is apparent that the variation of frame conditions described in the previous section leads to substantial differences in charging infrastructure requirements and battery investments. However, the quality of the impact also varies with each bus line.

\subsection{Energy consumption simulation}

The simulated energy consumption values are markedly different comparing the bus routes. Figure 1 shows the consumption for every bus line per round trip and per day respectively for one bus in operation. For the round trip consumption the trip with maximum consumption during daily operation is shown. 


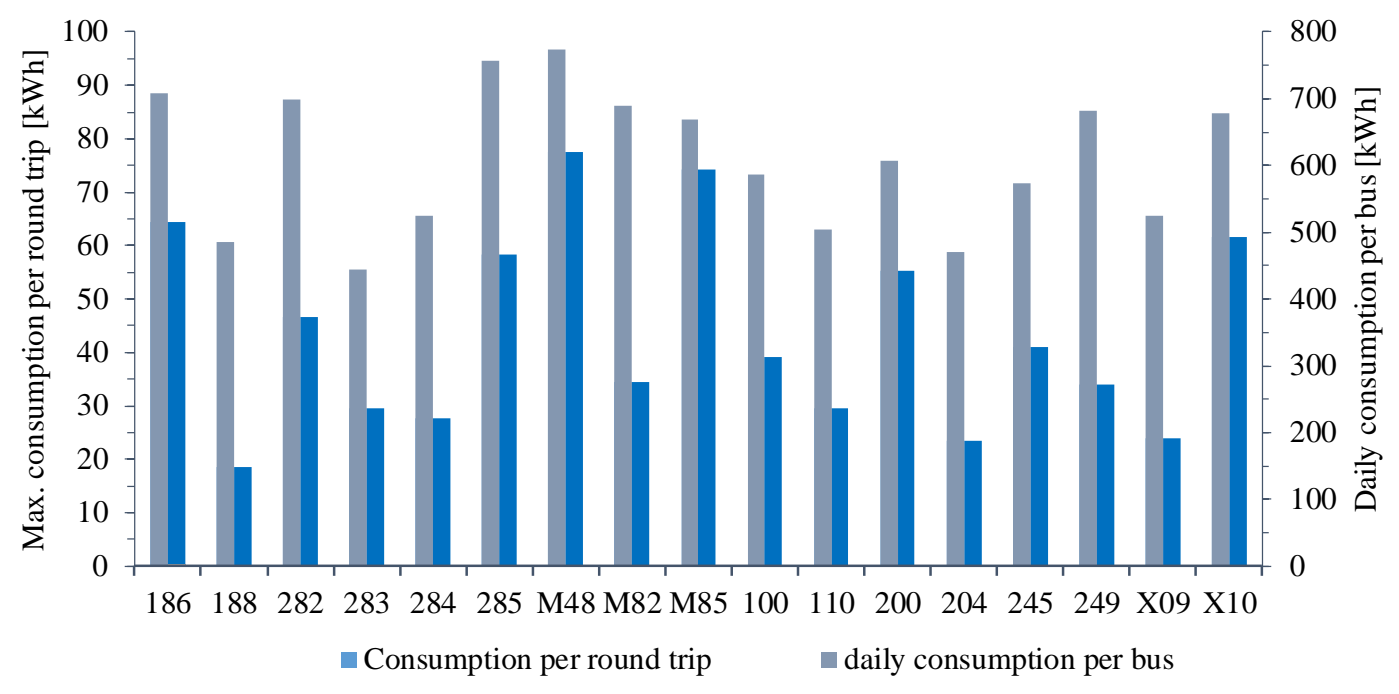

Figure 1: Energy consumption per round trip and per day and bus for each bus line

\subsection{Required charging infrastructure for investigated bus network}

The final results for the baseline scenario are presented in Figure 2. The selected bus stops for charging are shown in orange. Next to the stops, the figure displays the number of installed charging stations as well as the number of bus lines served by this charging station. In addition, Table 6 provides a network overview of key figures under the assumptions of the baseline scenario.

Table 6: Network overview for the simulated baseline scenario

\begin{tabular}{lcccccc|}
\hline Bus line & Bus type & $\begin{array}{c}\text { Line length } \\
{[\mathrm{km}]}\end{array}$ & $\begin{array}{c}\text { No. of } \\
\text { buses }\end{array}$ & $\begin{array}{c}\text { Battery capacity } \\
{[\mathrm{kWh}]}\end{array}$ & $\begin{array}{c}\text { Charging } \\
\text { points used }\end{array}$ & $\begin{array}{c}\text { Charging usage } \\
\text { during idle time }\end{array}$ \\
\hline 186 & DD & 27.87 & 12 & 90 & 3 & $80 \%$ \\
\hline 188 & SB & 11.27 & 4 & 60 & 1 & $70 \%$ \\
\hline 282 & DD & 19.32 & 8 & 90 & 2 & $64 \%$ \\
\hline 283 & SB & 17.65 & 6 & 60 & 1 & $78 \%$ \\
\hline 284 & SB & 16.83 & 4 & 60 & 2 & $62 \%$ \\
\hline 285 & DD & 26.21 & 6 & 90 & 3 & $60 \%$ \\
\hline M48 & DD & 33.35 & 12 & 90 & 3 & $85 \%$ \\
\hline M82 & DD & 13.61 & 8 & 90 & 2 & $64 \%$ \\
\hline 100 & DD & 32.67 & 14 & 90 & 4 & $73 \%$ \\
\hline 110 & DD & 15.64 & 10 & 90 & 4 & $95 \%$ \\
\hline 200 & SB & 19.64 & 4 & 60 & 3 & $67 \%$ \\
\hline 204 & DD & 23.61 & 10 & 90 & 5 & $91 \%$ \\
\hline 245 & SB & 12.73 & 4 & 60 & 3 & $50 \%$ \\
\hline 249 & AB & 15.62 & 10 & 90 & 3 & $76 \%$ \\
\hline X09 & AB & 13.89 & 6 & 90 & 3 & $98 \%$ \\
\hline X10 & DD & 34.56 & 6 & 90 & 3 & $43 \%$ \\
\hline Total & & 350.02 & 134 & & 3 & $66 \%$ \\
\hline
\end{tabular}

For the electrification of the entire network a total number of 24 charging stations is required. The charging points are located at terminal stops as well as at bus stops en route. All of the charging stations which are installed en route are located at intersection with other bus lines and thus feature cost synergies. 


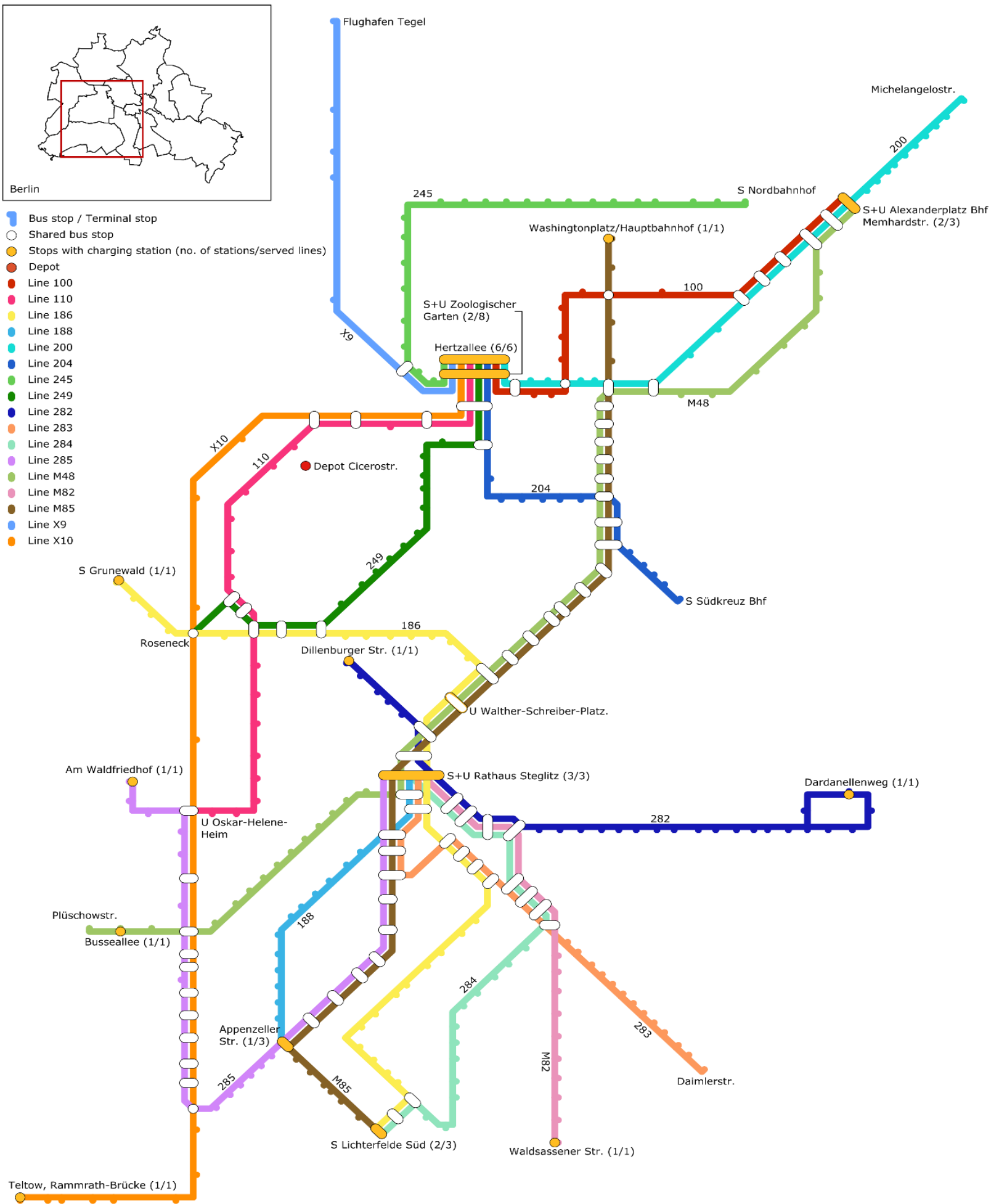

Figure 2: Bus network and charging stations for the baseline scenario. Number of charging stations and number of bus lines served are given in brackets.

Figure 3 presents the initial electrification cost including the base bus without batteries, the battery system and the fast charging infrastructure per bus and bus route for the baseline scenario. Moreover, the bus type and battery capacity for each bus line is displayed. The infrastructure cost are allocated in proportion to the number of lines using a charging station. The buses are equipped with the smallest possible battery size respectively to the bus type. The proportion of charging infrastructure and initial electrification cost varies between $4 \%$ and $16 \%$ depending on the bus line. The highest costs for charging infrastructure per bus occur for bus lines 285, 110 and 204. 


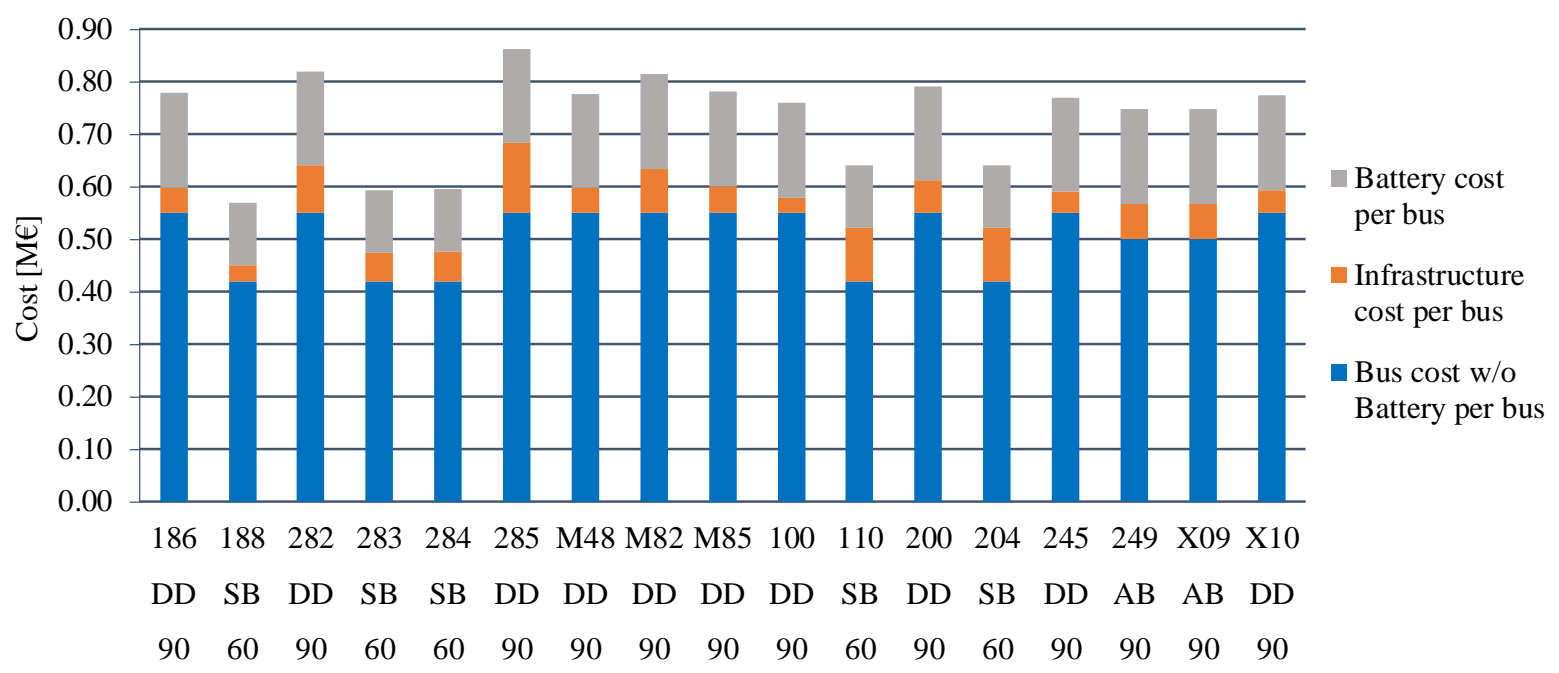

Figure 3: System costs per bus and bus route for the baseline scenario. The bus type and the battery capacity in kWh are given below the bus line number.

As illustrated by Figure 4 the total acquisition cost of each bus line fleet varies considerably for the respective bus line mainly caused by the number of operating buses. Bus lines M85, M48 and 186 show the highest total cost for electrification whereas bus route 285 and 282 reveal the highest cost for charging infrastructure. The total infrastructure for the simulated bus network of $350 \mathrm{~km}$ operated by 134 buses amounts to 8.12 million $€$, compared to battery cost of 22.80 million $€$ and vehicle cost (without batteries) of 70.24 million $€$. Therefore, the charging infrastructure for the electrification of the bus network amounts to around $23,200 €$ per bus route $\mathrm{km}$. For comparison purpose to other electrification technologies such as trolley bus systems, the cost for infrastructure and batteries considered together. Thus, the electrification cost amounts to around $88,300 €$ per bus route $\mathrm{km}$.

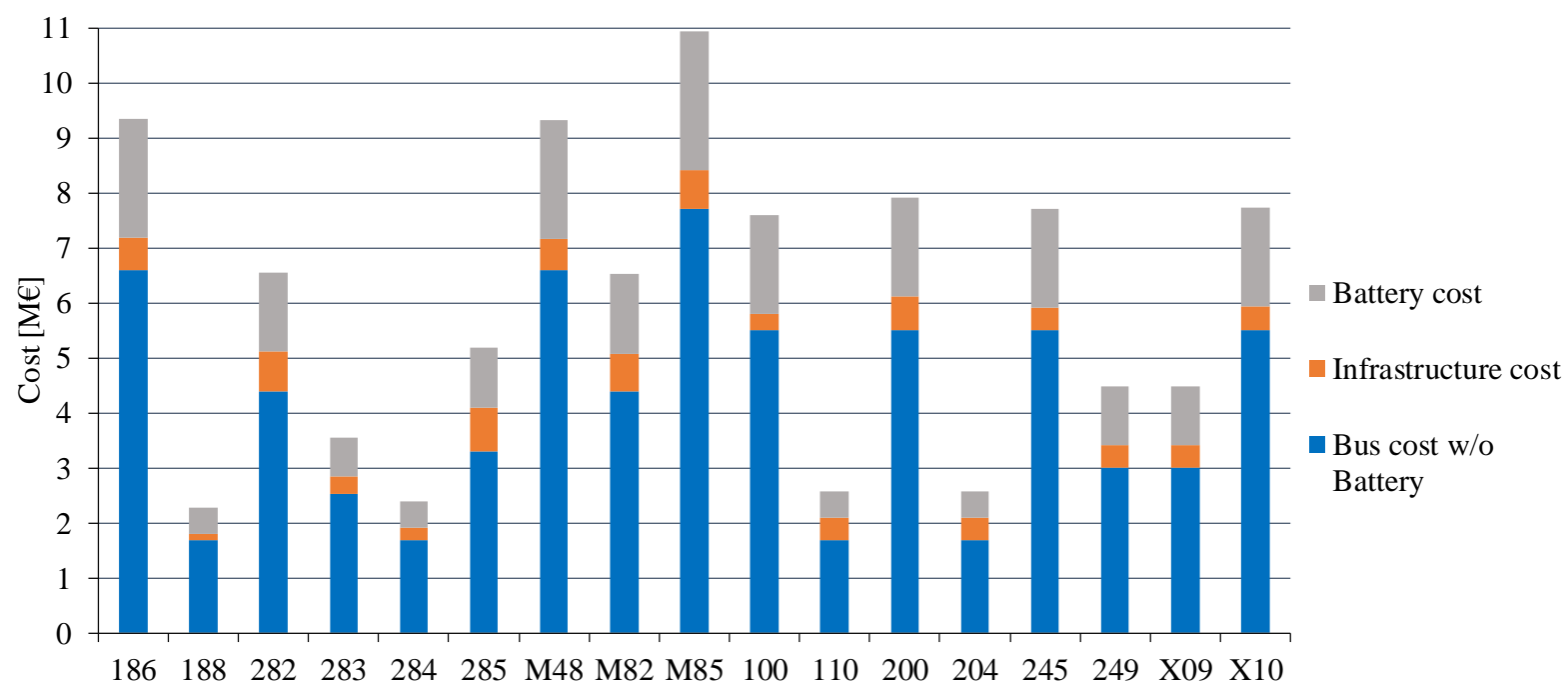

Figure 4: System cost per fleet and bus route for the baseline scenario

The summary of the results for all scenarios is shown in Figure 5 where cost of charging stations and batteries are presented. Changes in infrastructure cost compared to the baseline scenario are given in percentage. 


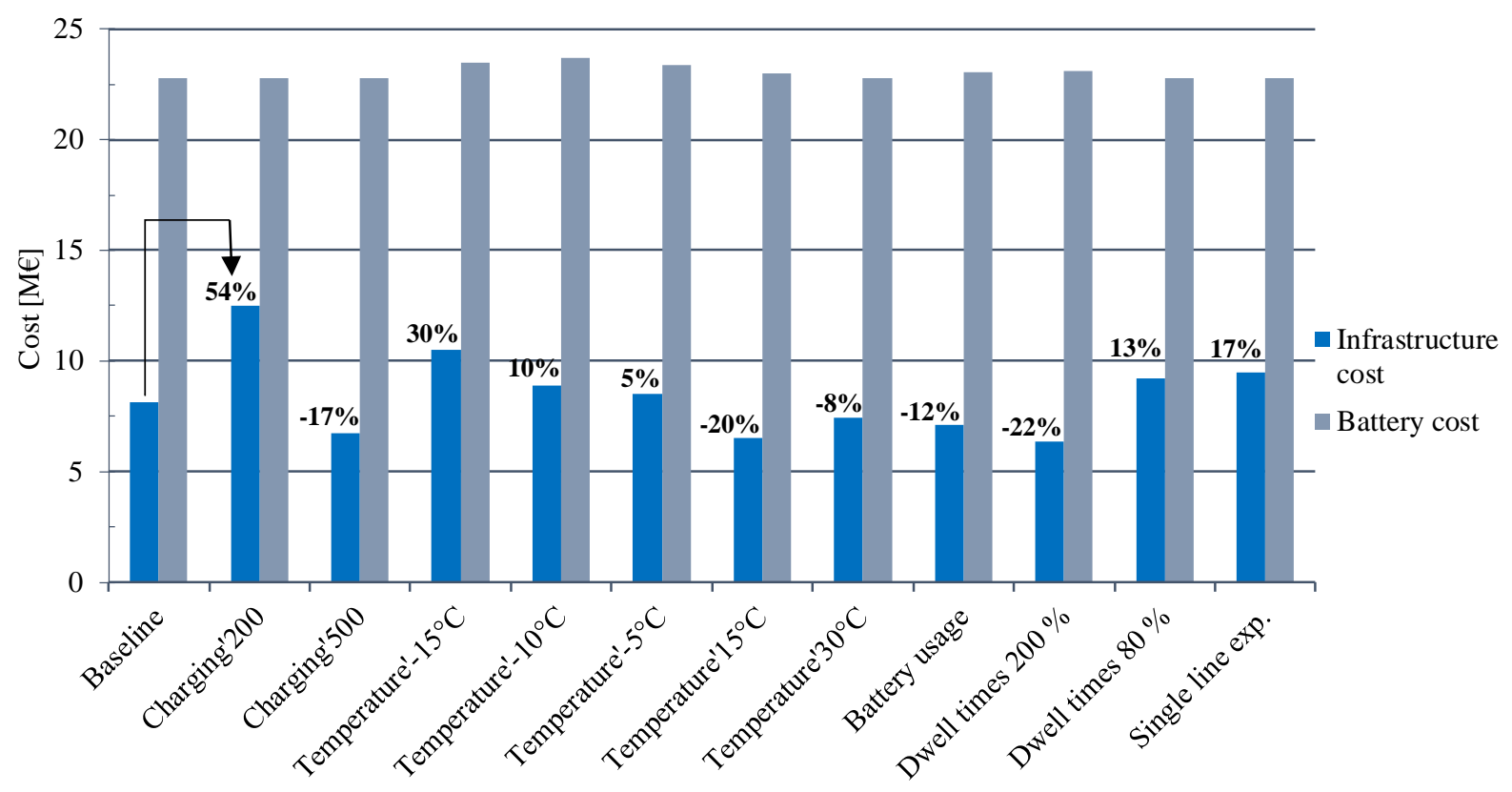

Figure 5: Charging infrastructure and battery cost for each scenario

Figure 5 shows that the charging infrastructure costs greatly differs between the considered scenarios whereas the battery costs are very similar. The high battery costs are caused by the number of buses which has to be equipped. In particular, the charging power has significant influence on the number of charging stations, which is consistent with the results obtained in previous studies [29-30]. The extension of dwell times also leads to distinctly lower infrastructure requirements. However, the extension of dwell times in real operation is only possible by adapting the operational schedule or by increasing the number of deployed buses. Furthermore, the bus routes benefit from sharing charging infrastructure. Comparing the results of the two different roll-out strategy cost savings in charging infrastructure of $17 \%$ could be realized through a network based approach. Furthermore, as it can be observed from Figure 5 the energy consumption for HVAC are relevant parameters affecting the complexity of infrastructure. The reduction of auxiliary power by means of a heat pump (scenario Temprature' $0{ }^{\circ} \mathrm{C}$ ) facilitates the implementation of fast charging bus systems.

Figure 6 presents the initial investment cost of batteries and charging infrastructure for the baseline scenario and different charging powers apportioned to the bus routes.

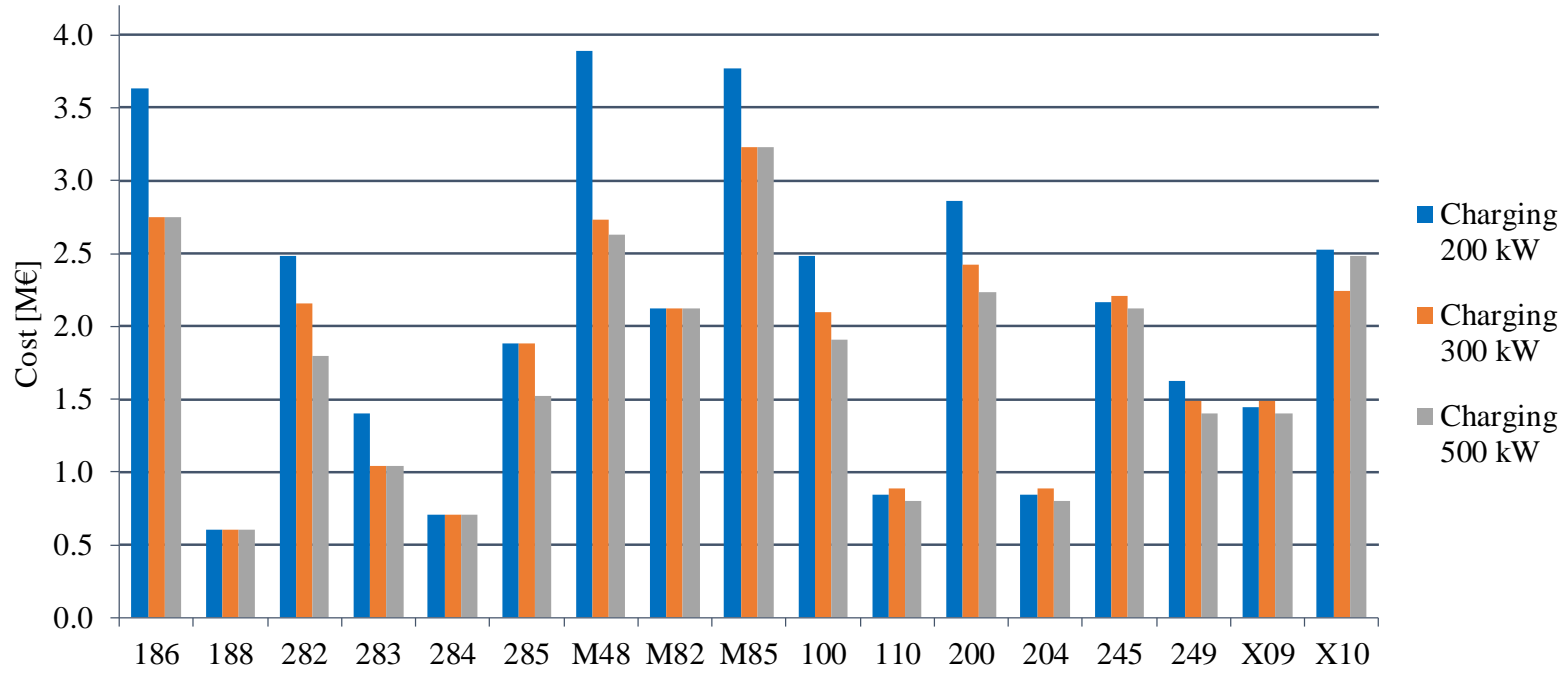

Figure 6: Battery and Infrastructure cost per fleet and route for baseline scenario by varying charging power 
Particularly, the power increase from $200 \mathrm{~kW}$ to $300 \mathrm{~kW}$ can reduce the investment cost for certain bus routes by $45 \%$ (line M48). Hence, a charging point and bus line specific power evaluation might reasonable in order to further reduce the electrification cost.

When comparing these results to the findings presented the recent study [32], it can be stated that for similar simulation conditions the costs for batteries can be reduced significantly through battery optimization. This underlines the importance of a joint optimization taking batteries and charging infrastructure into account.

The conducted sensitivity analysis revealed the monetary impacts of changed technology-related and operating conditions. Depending on the chosen simulation conditions for electrification, further analysis on the system stability and robustness might be reasonable to support the system layout. As a first indication how the electric bus system is able to cope with incidents causing an unexpected higher charging demand during operation, the utilised capacity of available charging time for the baseline scenario is evaluated as shown in Table 6 . The values are given as a proportion of charging time and available idle time at charging stations. For instance, bus line 248 is using $98 \%$ of its available charging time and thus the system is limited to withstand deviations from simulation assumptions.

\section{Conclusions}

In this study an advanced optimization model for planning a fast charging infrastructure for an urban bus network is introduced. A mixed-integer linear optimization model was developed to minimize the electrification costs, incorporating the trade-off between battery capacity and charging infrastructure. The applied model determines the minimum required number and respective location of charging stations as well as the optimal battery sizes for each bus line of a real network while ensuring a sufficient energy supply for daily operations. In order to assess the economic impacts of operational and technology-related constraints, several scenarios were examined. The sensitivity analysis reveals that the requirements of charging infrastructure and battery capacity is highly dependent on the applied assumptions. It is demonstrated that rather the charging infrastructure than the battery size compensates for changing operating environment. Once the minimum battery capacity for each bus line is identified, the parameter variations mainly affect the charging infrastructure. In particular, the charging power indicate remarkable potential to lower the infrastructure cost. Furthermore, the energy consumption of the HVAC system has substantial impact on the infrastructure requirements. The energy efficient supply of heat and cooling is crucial for a cost-effective infrastructure layout.

This study therefore indicates the economic benefits gained from operational and technology-related adjustments. The model is a sophisticated tool for planning and optimizing fast-charging electric bus systems and supports transit operators assessing a feasible electrification of bus routes. The final decision on the layout conditions remains open to the bus operators at this point. It should be noted that a system layout under extreme assumptions for multiple operating and technology-related conditions can lead to an excessively oversized bus system. Different options to mitigate the oversizing such as the temporary deployment of extra vehicles should be considered.

However, some limitations are worth noting. Although different charging powers were considered, the individual required power for a charging station was not investigated. Assuming that cost of charging stations might vary with the charging power, further research should examine the required charging power for every charging station individually in order improve cost-effectiveness. Furthermore, research should be done concerning the compatibility of simultaneously fast charging and energy grid capability within a network.

\section{Acknowledgements}

The authors would like to thank the participants of the DIW Brown Bag Seminar for their valuable comments and suggestions.

The authors gratefully acknowledge the financial support provided by the German Federal Government. This research was carried out as a part of the German Federal Government's Showcase Regions for Electromobility, the funding is issued by the Federal Ministry of Transportation and Digital Infrastructure. 


\section{References}

[1] U.-D. Choi et A1., Commercial operation of ultra low floor electric bus for Seoul city route, ISBN 978-14673-0953-0, Piscataway, IEEE, 2012.

[2] K. Erkkilä et Al., eBUS - Electric bus test platform in Finland, EVS27 International Battery, Hybrid and Fuel Cell Electric Vehicle Symposium, Barcelona, 2013.

[3] J. Laurikko et Al., Electric city bus and infrastructure demonstration environment in Espoo, Finland, EVS28 International Electric Vehicle Symposium, Goyang, 2015.

[4] Oprid, http://www.opbrid.com/ opbridco/images/eevc\%20umea\%20fast $\% 20$ charged\%20hybrids\%20final.pdf, accessed on 2015-05-06.

[5] L. Festner et Al., Foothill Transit Ecoliner Electric Bus Program, EVS26 International Battery, Hybrid, and Fuel Cell Electric Vehicle Symposium, Los Angeles, 2012.

[6] J. Miles et Al., Developing a viable electric bus service: the Milton Keynes demonstration project, Research in Transportation Economic, DOI 10.1016/j.retrec.2014.09.063, (48)2014, 357-363.

[7] D. Goehlich et Al., Stochastic Total Cost of Ownership Forecasting for innovative Urban Transport Systems, DOI 10.1109/IEEM.2013.6962529, Piscataway, IEEE, 2013.

[8] FCH JU - The Fuel Cells and Hydrogen Joint Undertaking, http://www.fch.europa.eu/node/790, accessed on 2013-02-10.

[9] IKT-EM, http://www.ikt-em.de/_media/Gesamtbericht_Wirtschaftlichkeit_von_Elektromobilitaet.pdf, accessed on 2015-05-10.

[10] O. Vilppo et Al., Feasibility of electric buses in public transport, EVS28 International Electric Vehicle Symposium, Goyang, 2015.

[11] J. Schwürzinger et Al., Report on Electrified Public Transport Bus System, Brussels, UITP, 2012.

[12] V. Marano et Al., Lithium-ion batteries life estimation for plug-in hybrid electric vehicles, ISBN 978-14244-2600-3 Piscataway, IEEE, 2009.

[13] A. Millner, Modeling Lithium Ion battery degradation in electric vehicles, ISBN 978-1-4244-6076-2, Piscataway, IEEE, 2010.

[14] I. Frade et Al., 2011. An optimization model for locating electric vehicle charging stations in central urban area, Journal of Transport Research Record: Journal of the Transportation Research Board, DOI 10.3141/2252-12, 2252(2011), 91-98.

[15] W. Tu et Al., Optimizing the locations of electric taxi charging stations: A spatial-temporal demand coverage approach, Transportation Research Part C: Emerging Technologies, DOI 10.1016/j.trc.2015.10.004, 65(2016), 172-189.

[16] P. Sadeghi-Barzani, et Al., Optimal fast charging station placing and sizing, Applied Energy, DOI 10.1016/j.apenergy.2014.03.077, 125(2014), 289-299.

[17] M. Cruz-Zambrano et Al., Optimal location of fast charging stations in Barcelona: A Flow-Capturing approach, ISBN 978-1-479-92009-9, Piscataway, IEEE, 2013.

[18] S. He et Al., Incorporating institutional and spatial factors in the selection of the optimal locations of public electric vehicle charging facilities: A case study of Beijing, China, Transportation Research Part C: Emerging Technologies, DOI 10.1016/j.trc.2016.02.003, 67(2016), 131-148.

[19] Z. Liu et Al., Optimal planning of electric-vehicle charging stations in distribution systems, Journal of IEEE Transactions on Power Delivery, DOI 10.1109/TPWRD.2012.2223489, 28(2013), 102-110.

[20] O. Worley et Al., Simultaneous vehicle routing and charging station siting for commercial, ISBN 978-1467-31562-3, Piscataway, IEEE, 2012.

[21] H. Kameda et Al., Optimization of Charging Station Placement by Using Taxi Probe Data for On-Demand Electrical Bus System, ISBN 978-3-642-23853-6, Berlin Heidelberg, Springer-Verlag, 2011.

[22] J. Barco et Al., Optimal Routing and Scheduling of Charge for Electric Vehicles: Case Study, http://arxiv.org/ftp/arxiv/papers/1310/1310.0145.pdf, accessed on 2015-06-20. 
[23] A. Boostani et Al., Optimal location of compressed natural gas (CNG) refueling station using the arc demand coverage, Proceedings of the 4th Aisia International Conference on Mathematical/Analytical Modelling and Computer Simulation, ISBN 978-1-424-47196-6, Piscataway, IEEE, 2010.

[24] R. Freling et Al., Vehicle Scheduling with Time Constraint, ISBN 978-3-540-60193-7, Berlin Heidelberg, Springer-Verlag, 1995.

[25] A. Haghani et Al., Heuristic approaches for solving large-scale bus transit vehicle scheduling problem with route time constraints, Transportation Research Part A: Policy and Practice, DOI 10.1016/S09658564(01)00004-0, 36(2002), 309-333.

[26] J. Reuer et Al., The Electric Vehicle Scheduling Problem: A study on time-space network based and heuristic solution approaches, Proceedings of the 13th Conference on Advanced Systems in Public Transport (CASPT), Rotterdam, 2015.

[27] C. Zhu et Al.,Optimizing Battery Electric Bus Transit Vehicle Scheduling with Battery Exchanging: Model and Case Study, Procedia - Social and Behavioral Sciences, DOI 10.1016/j.sbspro.2013.08.306, 96(2013), $2725-2736$.

[28] G. de Filippo et Al., Simulation of an electric transportation system at The Ohio State University, Journal of Applied Energy, DOI 10.1016/j.apenergy.2013.09.011, 113(2014), 1686-1691.

[29] T. Paul et Al., Operation and Charging Scheduling of Electric Buses in a City Bus Route Network, 17th International IEEE Conference on Intelligent Transportation Systems (ITSC), DOI 10.1109/ITSC.2014.6958135, 2014, 2780-2786.

[30] M. Rogge et Al., Fast Charging Battery Buses for the Electrification of Urban Public Transport-A Feasibility Study Focusing on Charging Infrastructure and Energy Storage Requirements, Energies, DOI 10.3390/en8054587, 8(2015), 4587-4606.

[31] K. Berthold et Al, Planung und Optimierung der Ladeinfrastruktur für E.Stadtbusse, Der Nahverkehr, ISSN 0179-504X, 7-8(2015), 16-20.

[32] A. Kunith et Al., Optimization of fast charging infrastructure for electric bus systems - Electrification of a city bus network, EVS29 International Electric Vehicle Symposium, Montreal, 2016.

[33] D. Goehlich et Al., Technology assessment of an electric urban bus system for Berlin, ISBN: 978-1-84564778-0, Southampton, WIT Press, 2014.

[34] T. Kurczveil, Energy transfer for electric traffic, ISBN 978-1-4673-7513-9, Piscataway, IEEE, 2015.

[35] VDE - Verband der Elektrotechnik Elektronik Informationstechnik e. V., https://www.vdv.de/statistik2014.pdfx?forced=true, accessed on 2016-02-02.

[36] DIN 70030, Kraftfahrzeuge, Ermittlung des Kraftstoffverbrauchs, Lastkraftwagen und Kraftomnibusse. Berlin, DIN, 1989.

[37] R. Schoblick, Antriebe von Elektroautos in der Praxis, ISBN 978-3-645-65166-0, Haar bei München, Franzis Verlag, 2013.

[38] T. Roeth et Al., Entwicklung von elektrofahrzeugspezifischen Systemen, DOI 10.1007/978-3-642-319860_6, Berlin Heidelberg, Springer-Verlag, 2013.

[39] D. Jefferies et Al., Energiebedarf verschiedener Klimatisierungssysteme für Elektro-Linienbusse, DKV Deutsche Kälte- und Klimatechnischer Verein e.V., Deutsche Kälte- und Klimatagung, Dresden, 2015.

[40] D. Goehlich et Al., Economic assessment of different air-conditioning and heating systems for electric city buses based on comprehensive energetic simulations, EVS28 International Electric Vehicle Symposium, Goyang, 2015.

[41] L. Lam et Al., Practical Capacity Fading Model for Li-Ion Battery Cells in Electric Vehicles, IEEE Transactions on Power Electronics, DOI: 10.1109/TPEL.2012.2235083, 12(2013), 5910-5918.

[42] M. Rogge et Al., Fast charging of battery buses and its impact on the aging of various Lithium-ion cell types, ISBN 978-3-937655-30-7, Brunswick, ITS Niedersachsen, 2013.

[43] B. Propfe et Al., Cost analysis of Plug-in Hybrid Electric Vehicles including Maintenance \& Repair Costs and Resale Values, EVS26 International Battery, Hybrid and Fuel Cell Electric Vehicle Symposium, Los Angeles, 2012.

[44] Bombardier, http://primove.bombardier.com/projects/europe/germany-berlin-primove-e-bus.html, accessed on 2015-11-9. 
[45] L. Nurhadi et Al., A Sensitivity Analysis of Total Cost of Ownership for Electric Public Bus Transport Systems in Swedish Medium Sized Cities, Transportation Research Procedia, DOI 10.1016/j.trpro.2014.10.058, 3(2014), 818-827.

[46] M. Pihlatie et. Al., Fully electric city buses - The viable option, ISBN 978-1-4799-6076-7, Piscataway, IEEE, 2015.

[47] ifeu - Institut für Energie- und Umweltforschung - Electric traction for buses, http://www.trolleymotion.eu/www/fileadmin/user_upload/EBus_Workshop_Berlin/EBus_Workshop_20.Mai_Berlin_Bergk_efu_Heidelberg.pdf, accessed on 2015-10-10.

[48] S. Anemüller, Bus-Linie 133 der KVB wird elektrisiert, Verkehr und Technik, ISSN 0340-4536, 2(2015), $50-54$.

[49] A. Uhlenhut, Erste Elektrobusse neuer Generation: Üstra Hannover erhält drei Fahrzeuge, Verkehr und Technik, ISSN 0340-4536, 4(2015), 122-125.

[50] VDV, VDV-Mitteilungen 2315 - Life Cycle Cost (LCC) bei Linienbussen, Cologne, beka Verlag, 2010.

[51] BYD Europe, http://bydeurope.com/vehicles/ebus/types/10_2.php, accessed on 2016-02-23.

[52] A. Laske, eBus - Von der Pilotlinie zum Linienbetrieb, Proceedings of the 7th VDV Conference Electric Buses - Market of the Future, Berlin, VDV, 2016.

\section{Appendix}

Table A.1: List of sets, parameters an variables of simulation model

\begin{tabular}{|c|c|c|}
\hline Sets & Description & Range \\
\hline$b$ & bus line & [unique identifier for bus line] \\
\hline FIRSTSTOP $_{n, b}$ & first stop on the route & $\epsilon[\mathrm{i}]$ \\
\hline$i, j$ & Bus stop & [unique identifier for each stop] \\
\hline id & bus station & [unique identifier for each station] \\
\hline $\operatorname{LASTSTOP}_{n, b}$ & bus stop just before the first stop & $\epsilon[\mathrm{i}]$ \\
\hline$n$ & number of round trips & $\epsilon[1, \mathrm{x}]$ \\
\hline$o$ & bus depots & $\epsilon[\mathrm{i}]$ \\
\hline$p$ & all stops except for depot & $\epsilon$ [ilo] \\
\hline$v$ & battery type & {$[\mathrm{kWh}]$} \\
\hline Parameters & Description & Unit \\
\hline$C_{v}^{B A T T E R Y}$ & cost of battery with capacity $v$ & {$[€]$} \\
\hline$C^{\text {STATION }}$ & construction cost of charging station & {$[€]$} \\
\hline$C^{\text {TRANSF }}$ & cost for transformer station & {$[€]$} \\
\hline$C A P_{v}^{\text {BATTERY }}$ & capacity of battery type $v$ & [kWh] \\
\hline CONSUME $_{i, j, b, n}$ & $\begin{array}{l}\text { energy consumed on route segment } i, j \text { on } \\
\text { line } b \text { in iteration } n\end{array}$ & {$[\mathrm{kWh}]$} \\
\hline IDLETIME $_{i, n, b}$ & $\begin{array}{l}\text { dwelling time of bus at stop } i \text { in iteration } n \\
\text { on line } b\end{array}$ & [s] \\
\hline$L_{B O U N D_{b}}$ & $\begin{array}{l}\text { Safety margin and lower bound for battery } \\
\text { discharge }\end{array}$ & {$[\%]$} \\
\hline$L P_{b}^{\text {high }}$ & loading power in the high power segment & {$[\mathrm{kW}]$} \\
\hline$L P_{b}^{l o w}$ & loading power in the low power segment & {$[\mathrm{kW}]$} \\
\hline MAXSTOPS $_{i d}$ & maximum number of stops at station id & [1] \\
\hline$N U M_{b}$ & number of buses on line $b$ & [1] \\
\hline$O V E R_{v}^{\text {BATTERY }}$ & $\begin{array}{l}\text { quotient of maximum battery size and the } \\
\text { battery size of option } \mathcal{V}\end{array}$ & {$[\%]$} \\
\hline POSTPROCESSING $_{b}$ & $\begin{array}{l}\text { post-processing time to terminate charging } \\
\text { process }\end{array}$ & {$[\mathrm{s}]$} \\
\hline PREPROCESSING $_{b}$ & pre-processing time to initiate charging & [s] \\
\hline
\end{tabular}




\begin{tabular}{|c|c|c|}
\hline & process & \\
\hline THRESHOLD & $\begin{array}{l}\text { threshold dividing the non-linear charging } \\
\text { function in different segments }\end{array}$ & {$[\%]$} \\
\hline Variables & Description & Unit \\
\hline$b a t_{b, v}$ & binary choice of battery type $v$ for bus line & $\{0,1\}$ \\
\hline$e_{i, n, b}$ & $\begin{array}{l}\text { energy level of line } b \text { in iteration } n \text { at stop } \\
i \text { after charging }\end{array}$ & {$[\mathrm{kWh}]$} \\
\hline$e_{i, n, b}^{\text {before }}$ & $\begin{array}{l}\text { energy level of line } b \text { in iteration } n \text { at stop } \\
i \text { after charging with high charging power }\end{array}$ & {$[\mathrm{kWh}]$} \\
\hline$i d l e_{j, n, b}^{h i g h}$ & $\begin{array}{l}\text { time charged in the high charging power } \\
\text { segment }\end{array}$ & [s] \\
\hline $\operatorname{idle}_{j, n, b}^{\text {low }}$ & $\begin{array}{l}\text { time charged in the low charging power } \\
\text { segment }\end{array}$ & [s] \\
\hline level $_{i, n, b}$ & $\begin{array}{l}\text { binary variable indicating corresponding } \\
\text { segment in the charging function based on } \\
\text { current SoC }\end{array}$ & $\{0,1\}$ \\
\hline $\operatorname{SOC}_{\mathrm{i}, n, b, v}$ & $\begin{array}{l}\text { state of charge (SoC) of battery type } v \text { at } \\
\text { stop } i \text { iteration } n \text { on bus line } b\end{array}$ & {$[\mathrm{kWh}]$} \\
\hline$z_{i}$ & charging station build at node $\mathrm{i}$ & $\{0,1\}$ \\
\hline$z_{\text {ident }}^{\text {id }}$ & Transformer station build at station id & [unique identifier for each station] \\
\hline
\end{tabular}

